\title{
Tetracycline Hydrochloride
}

National Cancer Institute

\section{Source}

National Cancer Institute. Tetracycline Hydrochloride. NCI Thesaurus. Code C48020.

The hydrochloride salt of tetracycline, a broad-spectrum naphthacene antibiotic produced semisynthetically from chlortetracycline, an antibiotic isolated from the bacterium Streptomyces aureofaciens. In bacteria, tetracycline blocks binding of aminoacyl-tRNA to the mRNA-ribosome complex, thereby inhibiting protein synthesis and bacterial cell growth. Because naturally fluorescing tetracycline binds to newly formed bone at the bone/osteoid interface, tetracycline-labeling of bone and fluorescence microscopy may be used to perform bone histomorphometry. 